\title{
O DESCONTÍNUO NA HISTÓRIA DA CULTURA COLONIAL E PÓS-COLONIAL: ACIDENTE OU FATALIDADE?*
}

\author{
Maria Helena P. T. Machado \\ Departamento de História-FFLCH/USP
}

RESUMO: O objetivo deste texto é apresentar algumas discussões de autores como Homi Bhabha, Mary Louise Pratt, Serge Gruzinski e Renato Rosaldo, que permitem pensar em formas alternativas de enfocar o tempo, a continuidade e descontinuidades da história.

PALAVRAS-CHAVE: História da Cultura, construção textual, continuidade e descontinuidades

ABSTRACT: Through a discussion of texts by Homi Bhabha, Mary Louise Pratt, Serge Gruzinski, and Renato Rosaldo, this article shows how these authors provide different ways of thinking about time, continuity, and discontinuity in history.

KEYWORDS: Cultural history, text, continuity, discontinuity

É muito bem-vindo como reflexão o tema da continuidade e descontinuidades quando pensamos na história da cultura. Pois este é um tema que nos remete imediatamente a uma outra questão fundamental ao historiador, que se coloca no próprio cerne de

\footnotetext{
* Este ensaio é uma versão revisada da prova escrita apresentada para o concurso de efetivação prestado na FFLCH.
}

seu fazer, que é a do tempo e das temporalidades. A questão das grandes linhas temporais e de suas descontinuidades é parte constitutiva de toda a reflexão, mas não temos a ambição de dar conta desta homérica tarefa de recuperar a historicidade das diferentes concepções de tempo, ou a historicidade das temporalidades. Objetivo muito mais modesto nos move.

Pretendo neste texto, partir da visão dos Annales, que se localiza, creio eu, na base da minha formação como historiadora, para pensar em formas alternativas de enfocar o tempo, a continuidade e desconti- 
nuidades da história, como elemento de análise das culturas não-ocidentais ou mestiças, isto é, culturas que expressam outras possíveis temporalidades. Bem como procurarei aqui pensar em estratégias que permitam conceber as descontinuidades históricas que são parte integrante destas culturas em fronteira, que são propriamente as culturas coloniais e pós-coloniais da América. Assim, como historiadora latino-americana, interessada, em termos amplos, na recuperação do processo de produção da história e da cultura nas áreas coloniais remeterei minha reflexão para a análise das especificidades de nossa inserção na aparente continuidade do onipresente mundo ocidental moderno globalizado.

Assim, relembro que a questão das grandes linhas temporais da história e suas descontinuidades, produtoras de diferentes abordagens do fato histórico, foi enfocada pelos Annales na forma de uma análise tripartida do tempo - a da longa duração, de caráter estrutural ou quase estrutural das mudanças lentas, imperceptíveis quando alijadas de um quadro seriado de longa envergadura, o das conjunturas, atingíveis pelo fatiamento do tempo segundo índices previamente escolhidos e o do evento, em sua aparente particularidade ${ }^{1}$.

Neste sentido, as diferentes estruturas da ação humana, projetadas na categoria do tempo são discriminadas pelo olhar do historiador, que ao se utilizar de diferentes estratégias analíticas, técnicas de pesquisa e conjuntos documentais, construiria narrativas históricas que expressariam as vicissitudes das diferentes dinâmicas da história. Assim, teríamos, o acompanhamento dos dados de longa duração, cujos

\footnotetext{
${ }^{1}$ Ver análise de BURKE, Peter. A Escola dos Annales. 1929-1986. São Paulo: Unesp, 1991, a respeito da estrutura temporal, conceito de civilização e princípio difusionista constantes dos trabalhos fundamentais dos mestres dos Annales como o de F. Braudel, em Mediterrâneo e mundo mediterrânico na época de Felipe II.
}

vetores expressam mudanças lentas ou lentíssimas, encontráveis no universo dos hábitos arraigados, costumes e crenças, e que por tal se coloca como o campo privilegiado da história da cultura. Mas também promove a história serial dos conjuntos econômicos, que se sobreporia ao tempo das conjunturas específicas, também seriadas, expressas em curvas cíclicas, portanto, em certo sentido, repetitivas e previsíveis, desde que se disponha do recorte certo e se faça a seleção de dados seriais correta e, finalmente, redundando no evento, com suas peculiaridades dinâmicas. Todas estas modalidades de concepção do tempo histórico implicariam na aceitação de descontinuidades, uma vez que a diferente dinâmica do comportamento do tempo histórico, pressuporia quebras de ritmos históricos e incompatibilidade das trajetórias temporais. No entanto, o encontro, ao menos teórico, de todas estas perspectivas históricas, projetaria no horizonte a possibilidade da síntese de todas estas temporalidades descontínuas, numa continuidade inclusiva de todo o tempo histórico - entendido, é claro, como todo o tempo histórico ocidental (BURKE, 1991, p. 51-52.

No entanto, à medida que a disciplina histórica, conjuntamente com outras disciplinas correlatas, como a antropologia e a crítica literária, tem pensado sobre o estatuto específico de uma história da cultura menos etnocêntrica, novos conceitos e concepções de temporalidade têm vindo à tona e feito parte dos acalorados debates que hoje os estudiosos do mundo pós-colonial ou em processo de descolonização têm encetado. Esta história seria necessariamente menos inclusiva e mais complexa em seus termos, porque arredia à absorção dócil aos padrões de uma história que pressupõe como perspectiva única, o tempo vazio e homogêneo do progresso (BENJAMIN, 1985, pp. 222- 234) tido como marco zero e origem de toda a história, mesmo da história das sociedades não-ocidentais, que apenas passariam à História com sua absorção enquanto sociedades coloniais. 
Neste universo teórico, que hoje chamamos genericamente de estudos culturais, quero lembrar aqui de alguns colaboradores, apenas a título de ilustração pois neste campo de discussões o que menos se pode encontrar é algum consenso. Sublinho os escritos de Homi Bhabha, atualmente o intelectual mais debatido no âmbito acadêmico e autor do recém-traduzido O Local da Cultura (BHABHA, 1998); Renato Rosaldo, antropólogo e autor do estudo clássico sobre os ilongots, e mais recentemente do livro fundamental para a crítica dos procedimentos da antropologia clássica, Culture and Truth (ROSALDO, 1989); Mary Louise Pratt, crítica literária e estudiosa da literatura de viagem dos séculos XVIII e XIX na África e na América hispânica, autora do também recém-traduzido, Os Olhos do Império (PRATT, 1999); e, finalmente, sublinho a contribuição de Serge Gruzinski em obras fundamentais para a discussão do estatuto mesmo da cultura mestiça, mexica e colonial, sobretudo em La Pensée Métisse (GRUZINSKI, 1999), esta agora em processo de tradução pela editora Companhia das Letras.

Todos estes autores, apesar de suas diferentes formações teóricas e especializações acadêmicas, têm hoje se voltado para a crítica do texto (aí incluso o documento histórico) e de sua textualidade num território teórico que evita a busca da homogeneidade e que não tem como meta autojustificadora o delineamento de linhas temporais coerentes. Em outras palavras, é este um esforço teórico que evita a busca das continuidades como fruto de um exercício intelectual consciente de descolonização do pensamento antropológico e etnográfico. A história da cultura é uma de suas grandes devedoras desta tendência, uma vez que será pela inclusão de certos procedimentos da etnografia e pela constatação, também proveniente do campo da etnografia, de que as sociedades não-ocidentais, também possuem solidez, organicidade e capacidade auto-reflexiva, é que vai inspirar os historiadores da cultura a se voltarem para os extensos campos da história da cultura popular, da história oral e para a historicidade das culturas até então consideradas como sem-história.

Será nas reflexões provenientes da análise textual e da recuperação etnográfica, que a história das sociedades "nativas" vai procurar inspiração. Neste campo analítico, conceitos como os de fronteira, descontinuidade e diferença serão fundamentais. Assim, por exemplo, comenta Renato Rosaldo ao fazer a crítica da visão clássica da teoria antropológica - que ele compreende como dos grandes autores até a década de 1960 - notando que "a mudança do pensamento social tornou as questões de conflito, mudança e desigualdades crescentemente urgentes. Os estudiosos não mais procuram a harmonia social, as fronteiras culturais mudaram de uma posição marginal para central" (ROSALDO, 1989, p. 28).

Fronteiras culturais, zona de contato, como conceituou Mary Pratt sobre o ambiente colonial no qual se deram os encontros entre as sociedades nativas e os viajantes naturalistas nos séculos XVIII e XIX na América e na África, produzindo uma abordagem na qual as análises a respeito de processos peculiares da história moderna do ocidente, com seu corolário de conceitos autoreferentes, e que são tomados como verdades onipotentes que prescindem de crítica exógena, como os de modernização, racionalismo, ilustração e romantismo, são necessariamente revistos. O axioma da constituição de um saber ocidental, construído no coração das metrópoles e transplantado para as zonas coloniais e pós-coloniais de "fronteira" é recusado. Afirma Mary Pratt, que é necessário rever nossa concepção a respeito das continuidades no desenvolvimento histórico europeu, a partir de uma nova dimensão global que inclua a fronteira, a zona de contato, suas especificidades e descontinuidades no aparentemente homogêneo e contínuo processo histórico do ocidente moderno. Neste empreendimento, a autora vai propor uma nova visão das relações entre as metrópoles e as áreas coloniais, entre o saber europeu e nativo, entre visitantes e visitados, en- 
tre viajantes e viajados (neologismo que a autora usa para sublinhar o caráter interativo destes encontros). A dimensão da autora é global - sem ser globalizante - e é, sobretudo, relacional e interativa, desprezando as análises unilaterais e pretensamente imparciais, mas que tomam, por princípio, aquilo que a autora denomina de literatura imperial (isto é, os escritos de viagem dos séculos XVIII e XIX) e o ponto de vista difusionista como verdade neutra e patamar básico de análise. Zonas de fronteira de conformação social, cultural e ideológica complexa, zonas de encontro de culturas, que se sobressaem também, no entender de Mary Pratt, como zonas de enfrentamento de diferenças, de tensão e dominação, territórios nos quais o sujeito ocidental se apropria do saber nativo, mas também espaço no qual o nativo apresenta a si mesmo, construindo identidades e saberes, moldando a percepção ocidental e conduzindo a construção de uma saber colonial, segundo parâmetros e visões de resistência que a história ocidental, assentada na certeza de sua superioridade e sapiência, tem enorme dificuldade de perceber.

Todos estes saberes e estilos de representação, produzidos no mundo colonial, conformam um colossal corpus de conhecimento, que foram sempre articulados e explicados pelo centro ou pelas metrópoles como um subproduto da influência da modernidade ocidental sobre contextos culturais portadores de alteridade, sempre representados por ausências ou lacunas. A não-racionalidade, o não-desenvolvimento econômico ou o atraso, o não-senso de tempo e história; são todos atributos que tomam como marco zero analítico a existência de um centro positivado pela presença dos atributos modernos e uma zona de fronteira ou periférica na qual a ausência serve de linha de contraste, produzindo a alteridade. Ora, as conseqüências deste tipo de análise, segundo Mary Pratt, aparecem bem claramente em duas direções que são fundamentais para a crítica do próprio conceito de modernidade (PRATT, 1999, pp. 17-54). Uma pri- meira diz respeito à constante necessidade demonstrada pelo ocidente moderno de encontrar sua própria centralidade por meio da exclusão e da delimitação de alteridades. Primitivos, irracionais, atrasados, prémodernos, são atributos por meio dos quais o ocidente moderno se projeta, excluindo de sua natureza o caráter contraditório de sua própria sombra, que é sempre relegada a uma periferia distante e para contextos culturais caracterizados pela fronteira e pela exclusão (PRATT, 1999, p. 44-52).

Não é difícil perceber o quanto este tipo de comportamento evoca processos culturais projetivos de expulsão da sombra, já bem descrita pela psicologia analítica junguiana. A expulsão de Lilith e dos atributos femininos "irracionais" enquanto estratégia para garantir a soberania da racionalidade do Deus masculino é um deles. O complexo Ceres/ Demeter, que opõe a juventude e frescor do feminino virgem à maldade e amargor do feminino maduro, visto como estéril e invernal, é ainda outro bem conhecido no qual a projeção do mal se associa tanto à perda da juventude, quanto à própria incapacidade do "feminino irracional" possuir uma dinâmica própria de evolução. Outro exemplo deste processo pode-se encontrar muito claramente definido no chamado complexo de bode expiatório, no qual pessoas ou grupos sociais são acusados de portar características intrínsecas estigmatizáveis e punidos por produzir má sorte. Ora, a questão é que o bode expiatório em sua versão bíblica, na figura do animal sacrifical oferecido aos deuses pela comunidade, contém o poder de aliviar os grupos sociais e indivíduos, por meio do contato com a dimensão transpessoal (divina) da comunidade, renovando os laços sociais. No entanto, se o ocidente moderno continuou presa do padrão bode expiatório, sendo ciclicamente compulsionado a apresentar suas vítimas, a dimensão divina foi perdida e ao bode expiatório passou-se a atribuir todos os males e defeitos sociais presentes na comunidade mas por ela negados. Assim, possibilitando que pela projeção da 
sombra, os perseguidores tenham a ilusão de serem "perfeitos, tanto quanto o Pai que está no céu e é perfeito" (Nesta análise me utilizei dos seguintes livros: KOLTUV, 1991; PERERA, 1981, PERERA, 1986). A seguinte passagem reflete bem esta posição: "Em termos junguianos, a atuação bode expiatório é uma forma de negar a sombra tanto do homem quanto de Deus. O que é visto como incapaz de conformar com o ego ideal ou com a perfeita bondade de Deus, é reprimido, negado ou fragmentado e tornado inconsciente".

Todos estes processos, que, aliás, conformam os fundamentos da psique ocidental, são localizáveis em qualquer discurso a respeito da modernidade e de seus outros. Tudo se passa como se incapaz de localizar seus aspectos contraditórios ou paradoxais em si mesmo, o discurso da modernidade se tornasse refém de sua própria sombra, projetada para aquilo que é entendido como os confins do território psíquico e não parte integrante dele, nas fronteiras de sua exclusão e em seus outros. Projetados, os aspectos negados, ganham clareza e retornam para o centro de maneira muito límpida, mas totalmente dissociada de sua fonte originária. Isto, é claro, se dá sempre por meio de um discurso transpessoal que encobre a dimensão individual da vivência desta espécie de discurso cultural. A análise de Mary Pratt, sob um outro ponto de vista, delineia o mesmo processo ao afirmar que o grande problema do discurso da modernidade é o de reiteradamente lançar mão de seus outros para se afirmar (PRATT, 1999, p. 50- 52).

Uma segunda questão, ainda segundo Mary Pratt, diz respeito às conseqüências provenientes da crença, propalada pelo discurso de dominação do centro moderno em direção às zonas coloniais e pós-coloniais, de que os processos de modernidade ocorrem nos países centrais como produtos de dinâmicas internas. Já a sua difusão, que afeta enormemente o destino das periferias, surge como mecanismo meramente auxiliar, quase acidental, cuja existência não produz impacto substancial na própria natureza autocentrada de seus processos. Segundo esta análise, os processos sociais coloniais e pós-coloniais são vistos como essencialmente reativos e seus produtos analisados segundo padrões de sucesso e fracasso em atingir os modelos centrais. Note-se, a academia e os cientistas sociais têm constantemente confirmado esta análise.

Esta abordagem, juntamente com o escrutínio da visão difusionista, que toma a história européia e seus processos sociais e culturais, eles próprios enfeixados e subsumidos às suas linhas dominantes, como gênese da vocação globalizante do ocidente e de suas grandes linhas em direção ao mundo colonial e pós-colonial, como ressalta Mary Pratt, devem ser confrontados com conceitos como o de cultura em fronteira, que colocam em relevo os processos sociais descontínuos em espaços geográficos e culturais peculiares e não-enfeixáveis facilmente nas grandes linhas continuistas da globalização do ocidente.

Abraçando um ponto de vista sensivelmente diferente, isto é, o da análise da produção da cultura no mundo da pós-modernidade, o teórico mais debatido atualmente no campo dos estudos culturais, Homi Bhabha, enfatiza a necessidade da quebra das visões culturais que se pautam pela busca da homogeneidade e continuidade, propondo um território de reflexão no qual "os limites epistemológicos das idéias etnocêntricas, são também fronteiras enunciativas de uma gama de outras vozes dissonantes" - entre as quais incluem-se as histórias das sociedades coloniais e pós-coloniais, acrescentando, o autor, que neste ponto de vista a fronteira é um lugar no qual, por meio de um movimento ambivalente, numa articulação cambiante e sempre descontínua "algo começa a se fazer presente" (BHABHA, 1998, p. 23-24). Assim, seria no fio cortante da tradução e da negação, num "entre-lugar" que poderíamos pensar o significado da cultura. Pois, seria o próprio hibridismo e instabilidade dos grupos culturais coloniais que os tornaria ativos e produtores de mudanças e revoluções. Em outras palavras, seriam os grupos sociais portadores de identidade hí- 
brida aqueles que carregariam as possibilidades de transformação e recriação social e cultural ${ }^{2}$.

Homi Bhabha, apesar de pertencer ao grupo de estudiosos da cultura dito pós-modernos, se volta decididamente contra a utilização de conceitos como o de relativismo cultural e multiculturalismo, que aparentemente se encontram na base do pensamento social que trouxe à cena histórica os grupos emudecidos pelo discurso abrangente da dominação, como o das minorias, mulheres, portadores de sexualidade "desviante" e as sociedades coloniais e pós-coloniais. E ele os recusa com a mesma intensidade com a qual contesta os mecanismos de produção de uma história homogênea, que encontra sua própria razão de ser na marcha que desenvolve em direção ao tempo vazio e homogêneo do progresso, da evolução e da vitória da racionalidade européia. Para Homi Bhabha, multiculturalismo e relativismo cultural, de fato, se reportam a conceitos liberais que se guiam pela crença nas possibilidades da coexistência da diversidade, fechando os olhos para os embates das diferenças ${ }^{3}$. Mais uma vez, a moldura teórica por ele proposta apela para um olhar não informado pela potencial harmonia social existente no conceito de diversidade, que seria alcançada pelo seu enfeixamento numa entidade neutra, colocada além do território descontínuo dos grupos sociais díspares, que é o do nacional ou da nação liberal e neoliberal.

\footnotetext{
${ }^{2}$ BHABHA, interpretando Fanon escreve: Para Fanon, o grupo liberatório que inicia a instabilidade produtiva da mudança cultural revolucionária é ele mesmo portador de uma identidade híbrida. Seus elementos estão presos no tempo descontínuo da tradição e da negociação, .. No momento da luta liberatória, o povo argelino destrói as continuidades e as constâncias da tradição nacionalista que fornecem uma salvaguarda contra a imposição cultural colonial. Eles estão livres agora para negociar e traduzir suas identidades culturais na temporalidade descontínua, intertextual, da diferença cultural, (p. 68).
}

Homi Bhabha reivindica um olhar que se volta para um entre-lugar, uma fronteira cultural, no qual se pode observar o choque das diferenças, e no qual as descontinuidades de universos culturais, semânticos e imagéticos se traduzem em embates políticos, e não desaparecem na entidade nacional e nem produzem a síntese que subjaz ao conceito de "povo". Em visão contrária, Bhabha advoga um horizonte político no qual o choque das diferenças continuamente produz dinâmicas culturais que são descontínuas em seu próprio modo de ser. Assim, postula-se uma contra-narrativa da nação, cujo estatuto continuamente evoca e rasura as fronteiras reais e conceituais da entidade nacional, perturbando as manobras ideológicas, como a utilizada por Benedict Anderson (ANDERSON, 1983) para explicar as independências latino-americanas e a eclosão dos nacionalismos em outras partes do globo, ao longo do XIX, e que concebem "comunidades imaginadas" como entidades portadoras de identidades essencialistas (BHABHA, 1998, p.211).

Aprofundando a crítica às visões que tomam as formações nacionais como representativas de um povo, entendido como a soma das diferenças na síntese do coletivo, Homi Bhabha pensa numa nova configuração do espaço nacional no qual o tempo sincrônico deixa de ser tomado como linha de continuidade explicativa do povo: "A firme marcação do tempocalendário, dá ao mundo imaginado da nação uma

\footnotetext{
${ }^{3}$ Bhabha, afirma, por exemplo: "A diversidade cultural é o reconhecimento de conteúdos e costumes culturais pré-dados; mantida em um enquadramento temporal relativista, ela dá origem a noções liberais de multiculturalismo, de intercâmbio cultural ou de cultura da humanidade. A diversidade cultural é também a representação de uma retórica radical da separação de culturas totalizadas que existem intocadas pela intertextualidade de seus locais históricos, protegidas na utopia de uma memória mítica de uma identidade única coletiva" (p. 63).
} 
solidez sociológica; ela une no palco nacional, atos e atores diversos, inteiramente despercebidos uns dos outros, exceto como uma função desse sincronismo do tempo, que não é prefigurativo, mas uma forma de contemporaneidade civil cumprida na plenitude do tempo" (BHABHA, 1988, p. 222-223). Da mesma forma que o conceito de nação teria que passar pelo crivo da crítica para se estabelecer em bases menos totalizadoras, o "outro" e os contextos culturais portadores de alteridade teriam que ser trazidos ao centro da cena, mas não como entidades a serem desvendadas pelo discurso etnográfico e percorridas por uma textualidade invasiva, mas sim como sujeitos históricos que iniciam uma ação e propõem uma inserção, com suas historicidades próprias, descontínuas e conflitantes.

Partindo da análise da história colonial da América, sobretudo da história da cultura e da arte, Serge Gruzinski também pensa sobre as questões aqui elencadas, discorrendo sobre processos culturais na fronteira (isto é, no mundo não-ocidental, colonial e pós-colonial) como produtores de dinâmicas culturais de mestiçagens, que não se enquadram na visão corrente deste fenômeno, entendido como melting pot, dissolvente das diferenças. Mas, sim, considerando que ao vivenciarem o processo de colonização e ocidentalização - preceito seminal à obra de Gruzinski - os grupos atingidos passaram a viver numa cultura de desaparecimento. Isto é, não culturas fadadas a desaparecer ao serem conspurcadas em sua pureza e integridade pelo contato com uma cultura européia dominante, mas sim culturas mestiças, e no mundo globalizado, elas são encontráveis tanto no metrô de Berlim e na linguagem cinematográfica de HongKong, quanto nas expressões culturais de índios coloniais, descontínuas em seu eterno fazer, obrigadas a tirar proveito da improvisação e da constante reinvenção a que estão submetidas devido ao seu próprio hibridismo (GRUZINSKI, 1999, p. 312- 316).

Todas as questões que foram aqui mencionadas de maneira ligeira perfazem um complexo campo de reflexões fundamentais para o historiador da cultura, interessado em recuperar as expressões culturais do mundo colonial e pós-colonial em seu caráter improvisado e multifacetado. Hoje, num universo teórico em que os "povos sem-história" foram trazidos à cena, e os grupos afrodescendentes e indígenas clamam pelo direito de fazer a própria história, os estudiosos se esforçam para achar o caminho, senão correto, menos danoso, para textualizar estas histórias, tarefa que nos torna vulneráveis a todos os perigos, e no qual nossas melhores intenções podem tornar-se nossas piores inimigas. Como nota Mary Pratt, seria necessário antes de tudo, estabelecer um contexto dialógico entre estas diferentes textualidades a nossa, letrada e a deles, oral, dominada etc - num território no qual os intelectuais momentaneamente abrissem mão de seu lugar de autoridade. Ao mesmo tempo, este intelectual teria que se manter alerta para a intrusão de dimensões idealizadas, que colocam no discurso do nativo, uma pureza e originalidade que amordaçam e destroem a criatividade da cultura idealizada, em nome de nossa própria incapacidade de abdicar do controle sobre o outro ${ }^{4}$.

Relembro, no entanto, as possibilidades de sucesso desta tarefa como ela se apresenta, por exemplo, no livro de Richard Price First Time (PRICE, 1983), e seu primoroso trabalho de registro da história oral e sagrada dos saramakas do Suriname escravos fugidos, quilombolas, que secularmente resistiram aos ataques dos escravistas e militares coloniais, encarniçadamente recusaram a reescravização e que acabaram estabelecendo co-

\footnotetext{
${ }^{4}$ PRATT, "Pós-colonialidade: projeto incompleto ou irrelevante?, op. cit., p. 42. No artigo, "Lucha-Libros: Me llamo Rigoberta Menchú y sus críticos en el contexto norteamericano", in: NuevaSociedade, Caracas, julho/ agosto, 1999, Pratt discute o lugar de autoridade do intelectual norte americano e seu papel político no contexto universitário norte americano.
} 
munidades livres em áreas recuadas da colônia assim permanecendo até a modernização da década de $1960^{5}$. O trabalho de dar corpo ou textualidade à memória sagrada dos bush negroes, em sua epopéia de fuga à escravidão, é recuperada numa concepção que não pretende sobrepor a nossa História à história deles ou mostrar como a história deles pode se tornar inteligível, desde que transcrita em nossos códigos. Pois em First Time, a história dos saramakas continua colocada no centro mesmo da produção de identidades culturais dinâmicas que alimentam os vivos. Mas um patamar dialógico é estabelecido por meio da sobreposição da versão nativa aos documentos e pesquisas levan- tados pelo pesquisador nos cânones acadêmicos da pesquisa histórica do século XX.

Assim, talvez, embora atravessada por uma nova textualidade, algo de sua dinâmica anterior, quem sabe seu próprio espírito rebelde, pudesse ser, de fato, preservado.Pois, era esta uma história que carregava um conhecimento enraizado na dimensão do sagrado e ao tocá-la os indivíduos se colocavam à mercê de suas conseqüências. "First Time mata as pessoas", como foi reiteradamente declarado nos testemunhos recolhidos por Price. De fato, enquanto a história se mantiver como fonte fundamental para a constante reinvenção de si mesma e do mundo, seu conhecimento permanece como assunto de vida e morte.

\footnotetext{
${ }^{5}$ Sobre a história dos saramakas e da escravidão nas Guianas, além do já citado First Time, consultar: PRICE, Richard (org. e introd). Maroon Societies. Rebel Slave Communities in the Americas. Baltimore: The Johns Hopkins University Press, 1979.
} 


\section{Bibliografia}

ANDERSON, Benedict. Imagined Communities. Reflections on the Origin and Spread of Nationalism. Londres/Nova Iorque, Verso, 1983.

BENJAMIN, Walter, "As Teses sobre a História" in Obras Escolhidas. Magia e Técnica, Arte e Política. São Paulo, Brasiliense, 1985, p. 222- 234.

BHABHA, Homi. O Local da Cultura (trad. Myriam Ávila e outros). Belo Horizonte, Ed. UFMG, 1998.

GRUZINSKI, Serge. La Pensée Métisse. Paris, Fayard, 1999.

KOLTUV, Bárbara B. O Livro de Lilith. São Paulo, Cultrix, 1991.

MACHADO, Maria Helena P. T. A Construção do olhar Imperial. Resenha do livro de Mary Pratt, Os Olhos do Império, in Revista Brasileira de História, no prelo.

PERERA, Sylvia Brinton. Descent to the Goddess. A way of initiation for women. Toronto, Inner City Books, 1981.
The Scapegaot Complex. Toward a mythology of shadow and guilt. Toronto, Inner City Books, 1986.

PRATT, Mary Louise, "Pós-colonialidade: projeto incompleto ou irrelevante?". In Literatura e História. Perspectivas e Convergências, Luiz Eugênio Véscio et alii (org). Bauru, Edusc, 1999, p. 17-54.

PRATT, Mary Louise. Culture and Truth. The remaking of social analysis ( $2^{\mathrm{a}}$ ed. de 1993 e com nova introdução).Boston, Beacon Press, 1989.

. Olhos do Império. Relatos de viagem e transculturação. Bauru, Edusc, 1999

PRICE, Richard. First Time. The Historical Vision of an AfroAmerican People. Baltimore, The Johns Hopkins University Press, 1983.

ROSALDO, Renato. Culture and Truth, Beacon Press, Boston, 1989.

Endereço da Autora: Depto. de História - FFLCH/USP - Av. Professor Lineu Prestes, 338 - Cidade Universitária - São Paulo - SP - Brasil - CEP 05508-900 - E-mail: 